\title{
Multi-scale mammal responses to agroforestry landscapes in the Brazilian Atlantic Forest: the conservation value of forest and traditional shade plantations
}

\author{
Aluane Silva Ferreira $\cdot$ Carlos A. Peres (D) Pavel Dodonov - Camila Righetto Cassano
}

Received: 21 February 2020/ Accepted: 4 September 2020/Published online: 3 October 2020

(C) The Author(s) 2020

\begin{abstract}
The future of tropical forest biodiversity will largely depend on human-modified landscapes. We investigated how medium- to large-bodied mammals respond to factors at local (habitat type), intermediate (land use heterogeneity, forest cover and human population density) and large spatial scales (overall forest cover) in agroforestry landscapes. We surveyed mammals using camera traps in traditional cacao agroforests (cabrucas), intensified cacao agroforests, and forest remnants within two large Atlantic
\end{abstract}

Electronic supplementary material The online version of this article (https://doi.org/10.1007/s10457-020-00553-y) contains supplementary material, which is available to authorized users.

\footnotetext{
A. S. Ferreira - C. R. Cassano

Post-Graduate Program in Ecology and Biodiversity Conservation, Applied Ecology and Conservation Lab, Universidade Estadual de Santa Cruz, Rodovia IlhéusItabuna, Km16 Salobrinho, Ilhéus, Bahia 45662-000, Brazil

C. A. Peres $(\square)$

Centre for Ecology, Evolution and Conservation, School of Environmental Sciences, University of East Anglia, Norfolk, Norwich NR4 7TJ, UK

e-mail: C.Peres@uea.ac.uk

C. A. Peres

Departamento de Ecologia e Sistemática, Universidade

Federal da Paraíba, João Pessoa, Brazil
}

Forest landscapes of southern Bahia, Brazil, representing both high and low forest cover. At the local scale, habitat types differed in their potential to harbour mammal species, with forest remnants and cabrucas showing high conservation value, mainly under contexts of high forest cover, whereas intensified cacao agroforests contained less diversified species assemblages in both landscapes. At intermediate scales, species richness increased with increasing forest cover around forest remnants and intensified cacao agroforests, but the opposite was observed in cabrucas. The effects of human population density were ubiquitous but species-dependent. At the largest scale, species richness was higher in the most forested

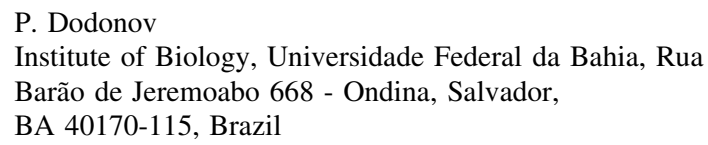


landscape, highlighting the imperative of maintaining forest remnants to retain forest-dwelling mammals in human-dominated landscapes. We claim that mammal conservation strategies require a multi-scale approach and that no single strategy is likely to maximize persistence of all species. Some species can routinely use traditional agroforests, and a large fraction of mammal diversity can be maintained even if high canopy-cover agroforestry dominates the landscape. Nevertheless, forest patches and highly forested landscapes are essential to ensure the persistence of forest-dwelling and game species.

Keywords Agriculture - Agroecosystem - Forest cover - Habitat type $\cdot$ Heterogeneity $\cdot$ Human density

\section{Introduction}

One-tenth of all largely intact ecosystems have been lost globally since the 1990s (Watson et al. 2016), and growing human populations coupled with food and biofuel demands will boost further agricultural expansion and intensification (Laurance et al. 2014). In this critical scenario, the future of biodiversity will largely depend on processes affecting population viability in human-modified landscapes (Gardner et al. 2009).

The effects of anthropogenic disturbance on biodiversity are scale-dependent. At local scales, factors such as vegetation structure influence local conditions, resource availability, and habitat quality. Because land uses differ in vegetation structure and composition, human-modified landscapes are usually comprised of environments with varying degrees of habitat suitability for native species (Daily et al. 2003; Harvey et al. 2006). For instance, traditional agroforests, with agricultural crops shaded by large trees, are identified as potentially wildlife-friendly systems (McNeely and Schroth 2006). Although structurally simpler than native forests, these croplands play an important role in biodiversity conservation, serving as habitat, connecting reserves, and alleviating pressure on resourceuse in protected areas (Bhagwat et al. 2008).

Local patterns, however, cannot be fully understood without considering the influence of the surrounding environment (Mazerolle and Villard 1999), whose features, such as the amount of native vegetation and degree of landscape connectivity and heterogeneity, frequently correlate with characteristics of species assemblages (Fischer and Lindenmayer 2007). Landscapes providing low habitat availability support fewer individuals and limited dispersal (Fahrig 2003), and loss of native vegetation around habitat remnants leads to native species declines worldwide (Estavillo et al. 2013; Pardini et al. 2017). Conversely, greater land use heterogeneity may increase biodiversity (Benton et al. 2003), as the diversity of land uses and consequently, a wider spectrum of resources available ensures accumulation of species requiring different habitats (Fahrig et al. 2011). Human population density is another strong indicator of threats to biodiversity (Luck 2007), related to habitat loss, spread of exotic species, and overhunting (Cardillo et al. 2004).

Considering the importance of surrounding native habitat, the appropriate spatial scale of a landscape remains controversial. Most often, the most appropriate landscape scale is defined in terms of the dispersal capacity of the study organism (Fahrig 2013), and few studies have addressed the importance of native habitat cover at very large spatial scales, thereby supporting entire populations (but see Faria et al. 2006; Pardini et al. 2010; Martensen et al. 2012). The role of scale in ecology is recognized as vitally important to understand ecological patterns and processes (Jackson and Fahrig 2015), and the scale at which modelling is performed can strongly influence model outputs (Cushman and McGarigal 2004).

Mammals play important ecosystem roles, including seed dispersal, predation, prey population control and herbivory (Wright 2003; Lacher et al. 2019) and have lost over $50 \%$ of their continental populations, mainly in densely settled landscapes (Ceballos and Ehrlich 2002). Worldwide, mammals often use agricultural matrices as part of their home ranges (Ferreira et al. 2018b), especially traditional agroforests that sustain multifunctional shade-trees (Harvey et al. 2006). Given the current loss of native ecosystems, a better understanding of the distribution and land use responses of mammals in agroforestry landscapes is crucial to avoid further population declines.

Here we investigate how mammal assemblages respond to land use change at different spatial scales: local (habitat type: forest, traditional cacao agroforest known as cabruca, and intensified cacao agroforest), intermediate (land use heterogeneity, percentage of forest cover, and human population density 
surrounding each site), and large scale (forest cover across the entire landscape, encompassing a group of sites at each county). We hypothesized that the strongest predictor of mammal assemblage would be the largest scale (Faria et al. 2007). At other scales, we expected that species richness, abundance and biomass would increase with habitat quality (forest $>$ cabruca $>$ intensified agroforest), forest cover and land use heterogeneity, and decrease with human population density (all settlements within $3000-\mathrm{m}$ of the sampling point). We also expected similar influences on assemblage structure, with higher impacts on mammal species that are most sensitive to anthropogenic disturbance.

\section{Methods}

Study area and sampling design

This study was carried out in southern Bahia, northeastern Brazil, where approximately 600,000 ha of land are occupied by cacao plantations (Landau et al. 2008). We surveyed mammals within two large landscapes that were spaced apart by $\sim 80 \mathrm{~km}$ : (1) largely covered by forest (50\% old-growth and midsuccessional forest cover and $15 \%$ cacao agroforestry; $15^{\circ} 03^{\prime}-15^{\circ} 16^{\prime} \mathrm{S}, 39^{\circ} 00^{\prime}-39^{\circ} 17^{\prime} \mathrm{W}$ ); and (2) mainly occupied by cacao farms, with small forest patches (5\% old-growth and mid-successional forest cover and $60 \%$ cacao agroforestry; $14^{\circ} 35^{\prime}-14^{\circ} 46^{\prime} \mathrm{S}, 39^{\circ} 08^{\prime}-$ $\left.39^{\circ} 17^{\prime} \mathrm{W}\right)$ (Fig. 1). These landscapes [hereafter referred to as high forest cover (HFC) and low forest cover (LFC), respectively], exhibit similar climate, original vegetation (Mori and Boom 1983; Thomas 2003) and mammal fauna (Prado et al. 2003).

The study was conducted at 30 cabrucas ( 15 sites at each landscape), 10 intensified cacao agroforests (five sites at each landscape) and 25 forests (15 sites at HFC and 10 at LFC). Cabrucas are complex stands where cacao trees (Theobroma cacao) are shaded by diverse canopy trees species (Rice and Greenberg 2000). Intensified agroforests are structurally simplified systems, with cacao cultivation largely or entirely shaded by exotic species, such as caja (Spondias mombin), Erythrina spp., jackfruit (Artocapus heterophyllus), palms (Euterpe oleracea), and rubber trees (Hevea brasiliensis). At the HFC landscape, rubber trees dominated the canopy layer of intensified agroforests
(29-93\% of trees), with few records of Erythrina spp. and jackfruit; whereas the LFC landscape included several exotic species (listed above) and rubber tree cover ranging from $0-73 \%$ (Fig. S1).

Sampling sites were spaced apart by a minimum distance of $800 \mathrm{~m}$, with exception of four forest sites, which were 120-293 m apart from cabruca sites. Cabruca sites were repeatedly sampled during four surveys, representing two seasons (warmest: JanuaryMarch; and coolest: June-August) in different years. Forest sites were surveyed up to four times, whereas intensified agroforest sites were surveyed only once in the warmest season. Sites at HFC and LFC landscapes were surveyed between 2016 and 2017 and between 2013 and 2017, respectively.

\section{Data acquisition}

Mammal sampling

We surveyed medium- to large-bodied mammals using one camera-trap (Trapa Camera or Bushnell) at each sampling site, $30 \mathrm{~cm}$ above ground, baited with sardine and banana. We included in our assemblages one small mammal, Didelphis aurita, and some arboreal species that were attracted to the bait and efficiently recorded on the ground (Cassano et al. 2012), but excluded Lontra longicaudis because our sample design could not efficiently record semiaquatic species. During each survey, cameras remained active for 30 days continuously and were checked weekly for maintenance and rebaiting. Due to camera-trap malfunction and variable sampling efforts between habitats, we obtained a total of 1569, 3382 and 290 camera-trap-days for forest, cabrucas and intensified agroforest, respectively. Our analyses account for differences in sampling effort.

Scale setting and variable extraction at the intermediate scale

We calculate the percentage of old-growth and midsuccessional secondary forest cover (hereafter forest cover) and land use heterogeneity (Shannon's diversity index, [exp. $\left.\left(\mathrm{H}^{\prime}\right)\right]$ ) within circular buffers around sampling sites. We used the diversity function in the vegan package (Oksanen et al. 2016) to calculate land use heterogeneity. The most appropriate landscape 


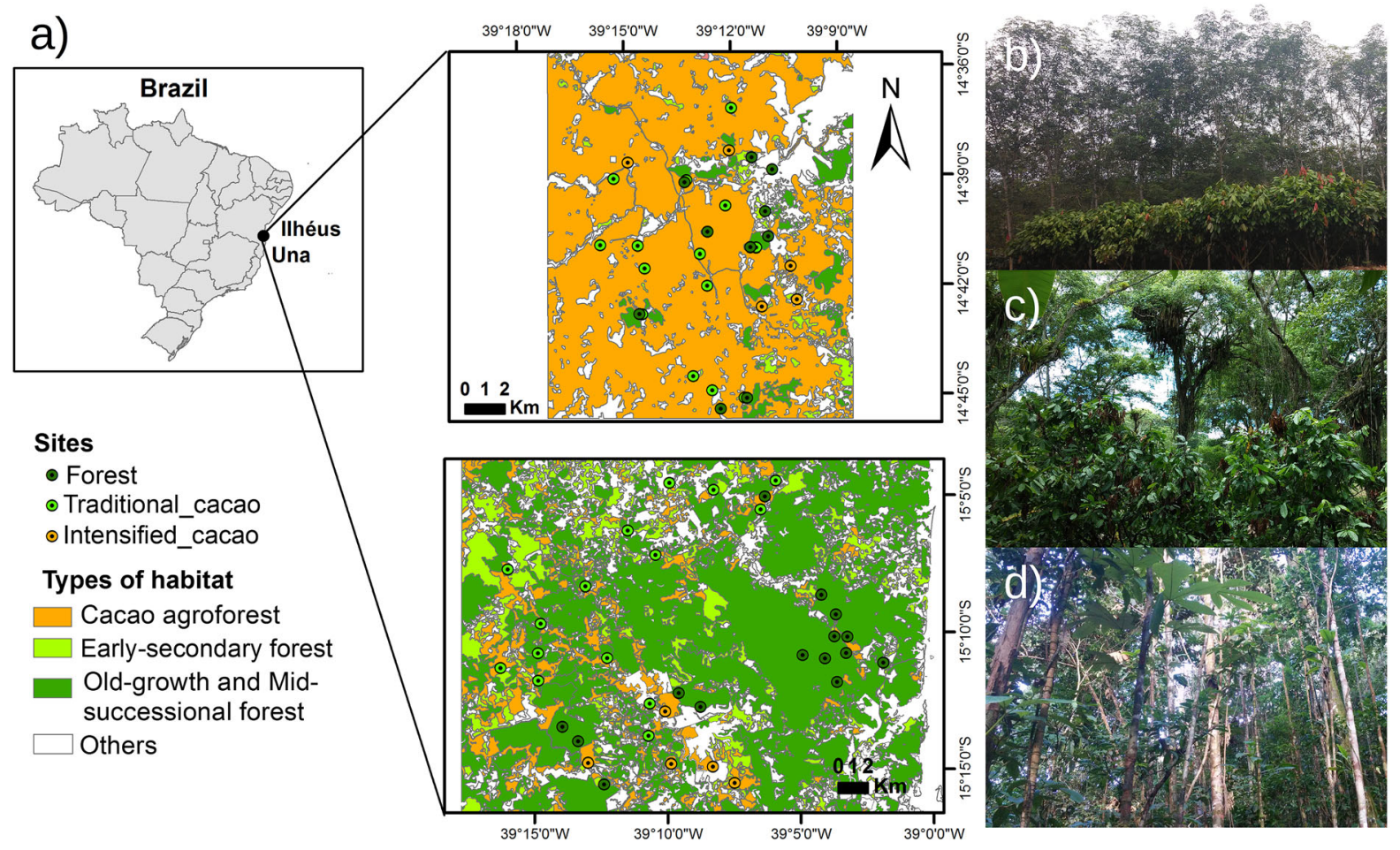

Fig. 1 a Distribution of sampling sites within the Atlantic forest, including 30 traditional cacao agroforests (cabrucas), 10 intensified cacao agroforests and 25 forest sites in Ilhéus (top panel) and Una (bottom panel), southern Bahia, Brazil. General

scale is often based on the dispersal capacity of the species of interest, and multi-scale analyses are highly recommended in assemblage-wide studies (Fahrig 2013). Both variables were quantified for buffer of 500, 1000, 1500 and $2000 \mathrm{~m}$ radius, which are often used in large mammal studies (Benchimol and Peres 2015; Beca et al. 2017; Regolin et al. 2017). To assess the spatial scale at which these landscape variables best explained estimates of mammal abundance, biomass and species richness, we constructed generalized linear models (GLMs) and used McFadden's pseudo- $\mathrm{R}^{2}$ values to assess the predictive strength of GLMs. The forest cover and landscape heterogeneity measured at 2000-m radius produced the highest pseudo- $\mathrm{R}^{2}$ values for most models (Table $\mathrm{S} 1$ ) and were used in further analyses.

We estimated neighbouring human population density (HPD, per $\mathrm{km}^{2}$ ) using circular areas of 2000 and 3000-m radius overlapping a spatial projection of census data from the Instituto Brasileiro de Geografia e Estatística (IBGE 2010) and used the 3000-m radius structural profile of surveyed habitats: b intensified cacao agroforest, shaded by rubber trees (Hevea brasiliensis), c cabruca, and $\mathbf{d}$ native old-growth forest

because (1) it produced stronger correlations with response variables in GLMs (Table S1) and (2) local residents in our study landscapes moved widely on foot or motorized vehicles.

\section{Data analysis}

We excluded images of the same species at the same site within a period of $24 \mathrm{~h}$ and calculated sampling effort (trap-days) excluding intervals of camera-trap malfunction to estimate four response variables: species richness, abundance, biomass, and assemblage structure. We estimated species richness using rarefaction and extrapolation, with Hill numbers ${ }^{0} \mathrm{D}$ (Chao et al. 2014), considering a standard effort of 50 photos, using the iNEXT package. We used this threshold because this was approximately twice the average number of photos per site, and most sites reached a species richness asymptote between 40 and 50 photos (Fig. S2). We calculated abundance as the sum of independent records of a given species at each 
site weighted by the sampling effort. Relative abundance is a reliable measure when true abundance estimates are difficult, and is positively related with independent density and abundance estimates (Carbone et al. 2001; Palmer et al. 2018). For biomass and community structure, we considered species capture rates (abundance/sampling effort $\times 30$ ) that represented the number of records expected for one survey period (30 days). We calculated biomass per site by summing the species-specific capture rates multiplied by the corresponding mean adult body mass (Wilman et al. 2014; Gonçalves et al. 2018).

We used GLMs to examine the influence of habitat type (local scale); forest cover, land use heterogeneity and HPD (intermediate scale); and landscape identity (HFC or LFC; large scale) on mammal species richness, abundance, and biomass. We log-transformed HPD and sqrt-transformed biomass prior to analyses. We examined the spatial autocorrelation in the residuals of the full models using variograms, which showed a lack of autocorrelation and consequently spatial independence among sampling sites (Fig. S3), and used the Generalized Variance Inflation Factor to test for multicollinearity between independent variables (Table S2). We applied stepwise multivariate regression analysis with backward selection until all remaining covariates had $p$ values $<0.05$, based on the likelihood ratio test (Zuur et al. 2009). Models were visually validated for homogeneity, normality, and independence (Zuur et al. 2009). Given our prior expectations, we included interactions between: landscape and habitat type, landscape and forest cover, and habitat type and forest cover in the full models. Effort was included as an offset term in abundance models. We used the negative binomial distribution for abundance models because of overdispersion and the Gaussian distribution for biomass and estimated species richness.

We used non-metric multidimensional scaling (NMDS; function metaMDS in the vegan package) to summarize patterns of assemblage structure, with Bray-Curtis dissimilarity for species capture rates. We used Permutational multivariate analysis of variance (Permanova: Anderson 2017) with 999 permutations to test if independent variables affected assemblage structure, using the adonis function in the vegan package. All analyses were performed in R 3.3.2 (R Core Team 2017).

\section{Results}

We recorded a total of 23 native and six exotic species. Domestic dogs were the most ubiquitous species, recorded at 47 sites. The most widespread native species were Cerdocyon thous (40 sites), Didelphis aurita (33), Eira barbara (33) and Callithrix kuhlii (30). Puma yagouaroundi and Sylvilagus brasiliensis were the most restricted species, with only one record each at cabrucas. We recorded three endangered species according to the International Union for Conservation of Nature (Callithrix kuhlii, Leontopithecus chrysomelas and Sapajus xanthosternos). S. xanthosternos was only recorded in forest sites while C. kuhlii and L. chrysomelas were recorded in all habitats but were more frequently recorded in cabrucas.

We observed 0 to 11 species per site. Species richness responded to landscape (HFC or LFC), proportion of forest cover, and habitat type, with a significant interaction between habitat type and both landscape $(p<0.01)$ and forest cover $(p<0.01$; Fig. S4a). Within landscapes, mean estimated richness was similar between forests and cabrucas (HFC: forest $=6.9 \pm 2.4$, cabruca $=6.9 \pm 2.7$; LFC: forest $=4.0 \pm 2.5$, cabruca $=5.2 \pm 2.7$; mean $\pm \mathrm{sd}$ ), but cabrucas in the HFC landscape contained more species than forests in the LFC landscape, and intensified agroforest had the lowest species richness $(\mathrm{HFC}=1.8 \pm 2.9, \mathrm{LFC}=1.8 \pm 1.8)$. Higher species richness was recorded at forests surrounded by greater amounts of forest cover, but the opposite was observed for cabrucas (Fig. 2a).

Mammal abundance was also affected by landscape, forest cover, and habitat type (Fig. S4b), with an interaction between habitat type and both landscape $(p<0.01)$ and forest cover $(p<0.01)$. Mammal abundance was lower in agroforests compared to forest sites, with a positive effect of forest cover only in intensified agroforests (Fig. 2b). Habitat type $(p<0.01)$ and the amount of surrounding forest $(p=0.03)$ affected the biomass of mammal assemblages but were depended of the landscape context (Fig. S4c). In general, biomass was lower in traditional agroforests than in forests, but cabrucas in the HFC landscape had higher biomass than forests in the LFC landscape. Biomass increased with forest cover in the HFC landscape but decreased in the LFC landscape (Fig. 2c). 
(a)

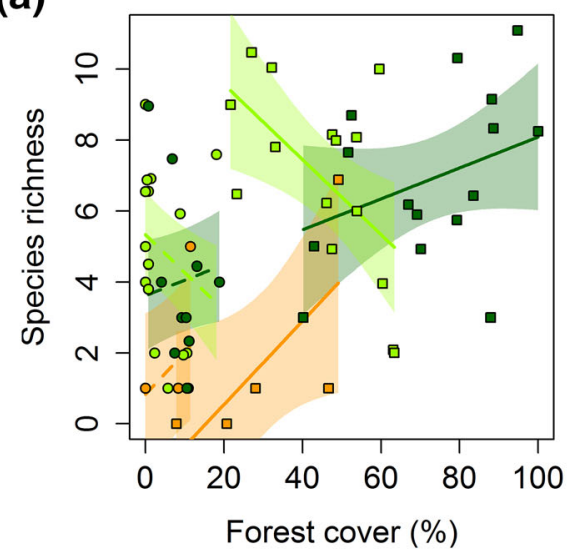

(c)

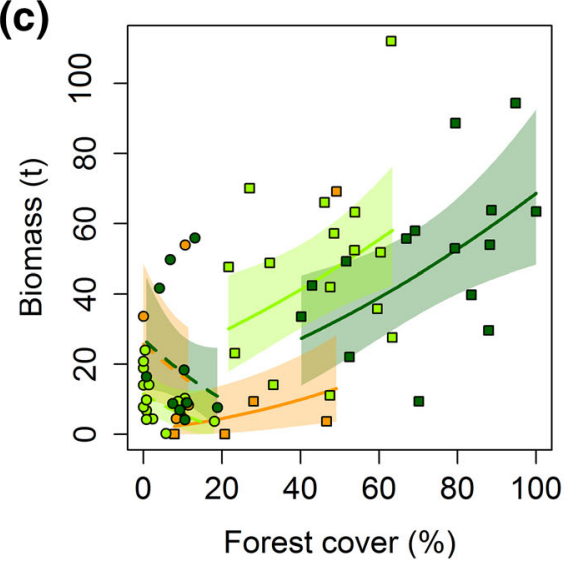

(b)

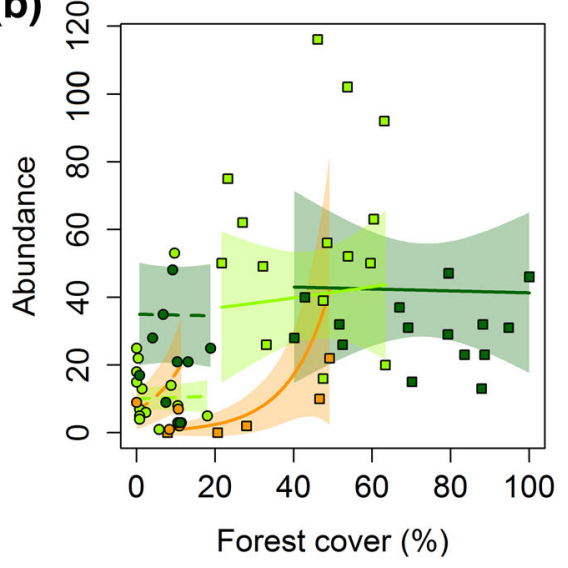

- LFC landscape

- HFC landscape

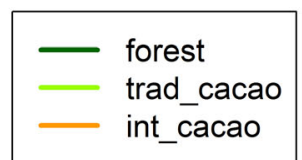

Fig. 2 Relationship between estimated a species richness, b overall abundance, and c total biomass and percentage of forest cover surrounding 65 sites surveyed at two landscapes in southern Bahia, Brazil: Low forest cover (LFC, dashed lines)

Mammal assemblage structure varied across landscapes $\left(\mathrm{R}^{2}=0.09, p<0.01\right)$, habitat types $\left(\mathrm{R}^{2}=0.10\right.$, $p<0.01)$, and along the HPD gradient $\left(\mathrm{R}^{2}=0.03\right.$, $p<0.01$ ) (Table S3). We also detected an effect of forest cover on assemblage structure, depending on habitat type $\left(\mathrm{R}^{2}=0.04, p=0.02\right)$. Eight forestdwelling species (Dasyprocta leporina, Mazama gouazoubira, Pecari tajacu, Potos flavus, Puma concolor, Puma yagouaroundi, Sciurus aestuans and Sylvilagus brasiliensis) were only recorded in the HFC landscape, whereas brocket deer (Mazama americana) was recorded only in the LFC landscape. Euphractus sexcinctus was more common in the LFC landscape, whereas Cuniculus paca, Didelphis aurita, Eira barbara and Tamandua tetradactyla were more common in the HFC landscape (Table S4). Four species and High forest cover (HFC, solid lines) landscapes. Midsuccessional and old-growth forest (forest), cabrucas (trad_cacao) and intensified cacao agroforests (int_cacao) are colourcoded in dark green, light green and orange, respectively

were entirely restricted to forest (Cabassous tatouay, P. flavus, Sapajus xanthosternos and S. aestuans) (Fig. S5). Species responses to human population density were variable. Pecary tajacu, P. flavus, P. concolor, $S$. aestuans and $T$. tetradactyla were most abundant at sparsely settled sites, whereas $C$. thous and $C$. kuhlii were most abundant in heavily settled areas (Fig. 3).

\section{Discussion}

Our results indicate that traditional cacao agroforests retains mammal conservation value, even in landscapes that are heavily dominated by this land use, while intensified cacao agroforests, with a low 


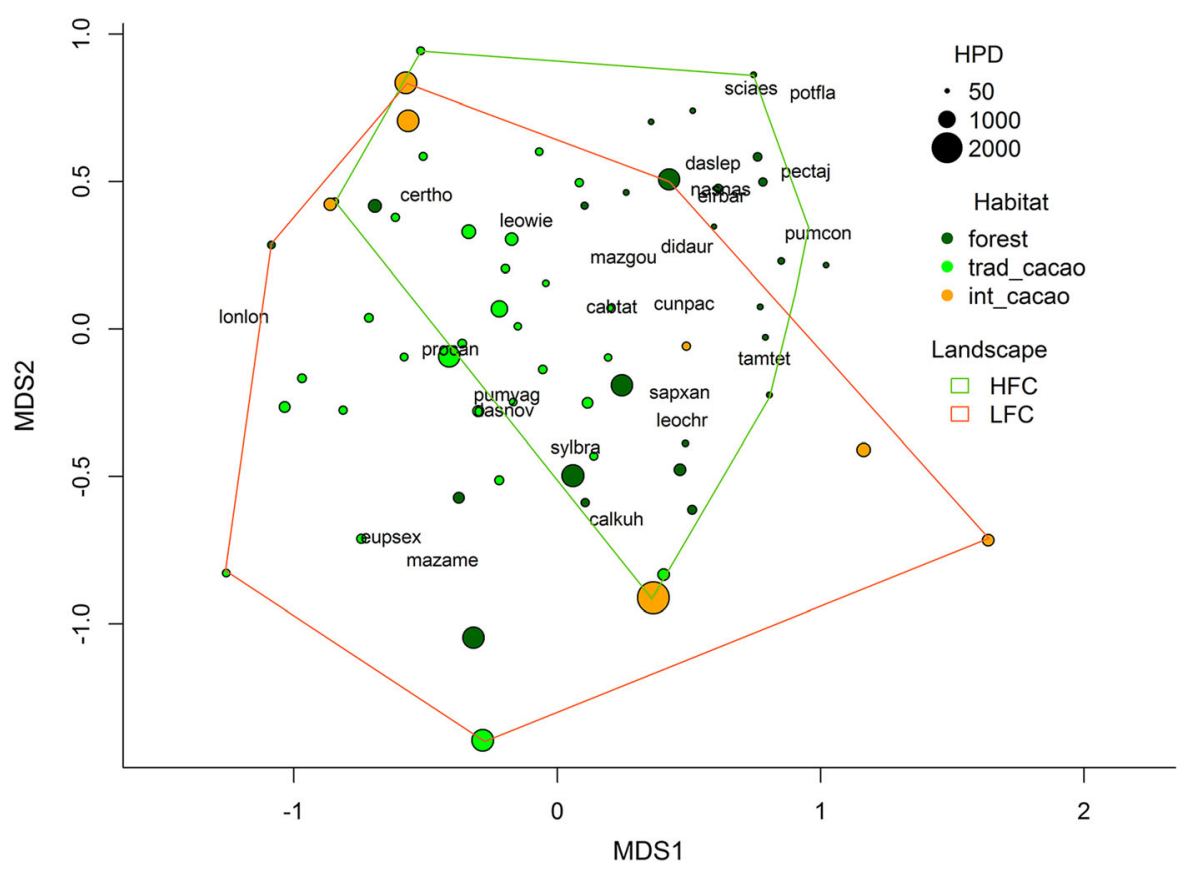

Fig. 3 Non-metric multi-dimensional scaling biplot (BrayCurtis dissimilarity) of the mammal assemblage structure (including medium- to large-bodied species) at 63 sampling sites in southern Bahia, Brazil. Symbols are sized according to human population density (HPD) and coloured according to habitat types [(forests (forest), traditional (trad_cacao) and

diversity of shade trees, were used by few species. Differently than expected, we found similar species richness between forest and cabruca sites within landscape. However, because some species occurred only in the most forested landscape (HFC), cabrucas in this landscape showed higher species richness and biomass than remaining forest patches in the LFC landscape. Some generalist species (C. kuhlii, C. thous and Procyon cancrivorus) sustained higher abundances in cabrucas in the HFC landscape compared to forests in the LFC landscape, contributing to the higher biomass at these sites. Nevertheless, forestdwelling species were largely restricted to and showed the highest abundances in forests, and were predominantly retained in the HFC landscape, indicating the irreplaceability of native habitat for their persistence in human-modified landscapes.

Predicting species persistence in agricultural landscapes requires an understanding of the surrounding habitat patches. Considering the role of habitat amount (surrounding forest cover), our findings were consistent with previous studies reporting higher vertebrate intensified cacao agroforests (int_cacao)]. The two landscapes sampled are included within convex hulls (HFC: high forest cover and LFC: low forest cover landscapes). Species Latin binomial codes can be found in Table S4 (see Electronic Appendix)

species richness and abundance at sites surrounded by high amounts of forest cover (Martensen et al. 2012; Cassano et al. 2014). Forest landscapes containing larger and more connected patches are less likely to be overhunted (Peres 2001) and ensure higher occupancy by large-bodied vertebrates (Magioli et al. 2016), which seems to be the case of our forest sites. In intensified agroforests, the positive effect of surrounding forest cover on mammal abundance may result from source proximity and a generally more benign context. The opposite pattern, however, was evident for species richness at cabrucas and biomass estimates at cabrucas within the LFC landscape. While cabrucas are considered suitable habitat for many mammal species (Cassano et al. 2012), they were more speciespoor in this study whenever surrounded by higher amounts of forest cover. It is likely that several species are sufficiently saturated by forest resources, thereby failing to exploit neighbouring cabrucas, wherever large forest areas are available. We suggest that the positive influence of forest cover on biomass in the HFC landscape, but not in the LFC landscape, can be 
attributed to differences in species composition and abundance between landscapes. As forest cover increased in the HFC landscape, large-bodied species such as M. gouazoubira, P. tajacu, E. barbara, T. tetradactyla were clearly favoured. In the LFC landscape the abundant $C$. thous and $P$. cancrivorus responded negatively to increasing forest cover. These species are typically described as habitat and dietary generalists, often thriving in agricultural habitats (Dotta and Verdade 2011; Cassano et al. 2014).

Several studies have found a positive correlation between land use heterogeneity around sites and faunal species diversity (e.g. Tews et al. 2004), but this is at odds with our results for the whole assemblage. In addition some threatened and habitatsensitive species may be detrimentally impacted in terms of lower densities or local extinctions by increased habitat heterogeneity even if this generally favours the entire mammal fauna. As our surveyed assemblage included few threatened and sensitive species, we believe that the lack of correlation can be attributed to the relatively low habitat quality contrast (especially between forests and cabrucas) and to the fact that landscapes sharing the same degree of heterogeneity can differ widely in spatial configuration.

Despite the importance of habitat complexity and surrounding context in maintaining mammalian diversity, little attention has been given to the characteristics of wider landscapes (but see Faria et al. 2007; Anand et al. 2010). Our study clearly shows that natural forests and cabrucas in the HFC landscape harbour more forest-dwelling species and more species-rich assemblages, containing more largerbodied species. This is consistent with a study on birds and bats in the same study areas, which emphasises the imperative of retaining native forest remnants to support biodiversity persistence in landscapes dominated by cacao agroforests (Faria et al. 2006). Yet the opposite pattern of lower mammal species richness, abundance and biomass was observed in intensified cacao agroforests even in the HFC landscape. This was almost certainly due to the dominance of species shading cacao trees in these sites and highlights the imperative of maintaining shade tree diversity to ensure the persistence of biodiversity (Santos et al. 2019).

Large mammal assemblages fare poorly in close proximity to human settlements due to habitat loss, overhunting, resource competition with humans and livestock, and diseases sourced from exotic animals such as domesticated dogs (Woodroffe 2000; Lessa et al. 2017). Mammal assemblage structure was affected due to changes in species composition and abundance in more heavily settled areas. Subsistence hunting by rural dwellers is still widespread in southern Bahia and several species that were absent or virtually absent in the most heavily-settled areas (C. paca, D. aurita, D. leporina, M. gouazoubira, $N$. nasua and $P$. tajacu), are important game species (Castilho et al. 2017), two of which (C. paca and P. tajacu) are also pursued by dogs in cabrucas (Santos et al. 2018). Conversely, species such as C. thous and C. kuhlii were more common in heavily populated areas, attesting their disturbance-tolerance. These species show high ecological and/or behavioural plasticity and may be favored by the absence of strict forest-dwelling species, as they side-step competition (Ferraz et al. 2010; Ferreira et al. 2018a).

The relatively low explanatory power of our models indicates a large degree of unexplained assemblage variability, but does not reduce the validity of our results, as even inaccurate ecological models can still be successful (Odenbaugh 2005). This low predictive power is typical of assemblage-wide studies, as community patterns involve more factors and greater complexity than single-species patterns (Low-Décarie et al. 2014). Factors such as hunting pressure, habitat resources and species interactions can diverge in how they influence mammal species. Yet our results bring important information about vertebrate use of forests and agroforestry under varying shade-management levels and landscape contexts, which are extremely valuable in informing wildlife conservation in anthropogenic landscapes.

Our study shows that agroforestry landscapes can harbour considerable mammal diversity in the Atlantic Forest biome, with patterns of land use predicting mammal assemblage structure at multiple scales. We highlight the potential for agroforests to support mammalian assemblages, as long as traditional shade management and sufficient areas of natural forests are retained within any given landscape. From a policy perspective, it is critical to note that agroforestry systems are currently permitted to replace native forests in privately protected areas in Brazil (in Legal Reserves: a percentage of rural property that needs to be preserved, and in Permanent Preserved Areas: e.g. 
river banks, spring and lake surrounds, slopes, hills, and mountain tops; Law No. 12,651, 25th May 2012). We emphasise that a widespread use of agroforestry systems at the expense of native vegetation will detrimentally affect mammal assemblages.

We claim that no single strategy is likely to maximize the retention of all mammal species and that mammal conservation strategies require a multiscale and multi-pronged approach. Some species can coexist with human populations and routinely use traditional agroforests as foraging or connectivity habitat, and a large fraction of the mammal fauna can persist even if agroforestry under high levels of tree canopy cover dominates the landscape. Nevertheless, forest patches and highly forested landscapes are essential to ensure the persistence of forest-dwelling and game species. We therefore highlight the critical importance of setting aside native forest remnants and managing agroforests to maintain a diversified canopy layer if forest-dwelling species are to persist in agroforestry landscapes.

Acknowledgements Thanks to Álvaro Olaechea, Ana Silva, Cláudia Santos, Lucas Moreno, Sérgio Lopes, Sirleide Santos and Rubens Vieira for help in fieldwork, and Martin Alvarez and Tadeu de Oliveira for identifying some species. This research was approved by the National Institute for Biodiversity Conservation (ICMBio), License Number 56993-1.

Author contributions ASF, CRC and CAP conceived the ideas and designed the methodology; ASF collected the data; ASF and PD analysed the data; ASF, CRC, CAP and PD led the writing of the manuscript. All authors contributed critically to the drafts and gave final approval for publication.

Funding This study was funded by FAPESB, IdeaWild, PróReitoria de Pesquisa e Pós-Graduação at Universidade Estadual de Santa Cruz and Rufford Foundation (19666-1). ASF scholarship was financed in part by the Coordenação de Aperfeiçoamento de Pessoal de Nível Superior - Brasil (CAPES) - Finance Code 001 and Fundação de Amparo ao Pesquisador do Estado da Bahia (FAPESB); PD received a postdoctoral grant from CAPES via the PNPD program.

Availability of data The dataset generated and analysed during the current study are available in the Mendeley repository: [https://data.mendeley.com/datasets/t8ykmzb7y4/ draft?a=94ddf909-b8f5-444e-8eea-291658f25949].

\section{Compliance with ethical standards}

Conflict of interest The authors declare that they have no conflict of interest.
Open Access This article is licensed under a Creative Commons Attribution 4.0 International License, which permits use, sharing, adaptation, distribution and reproduction in any medium or format, as long as you give appropriate credit to the original author(s) and the source, provide a link to the Creative Commons licence, and indicate if changes were made. The images or other third party material in this article are included in the article's Creative Commons licence, unless indicated otherwise in a credit line to the material. If material is not included in the article's Creative Commons licence and your intended use is not permitted by statutory regulation or exceeds the permitted use, you will need to obtain permission directly from the copyright holder. To view a copy of this licence, visit http://creativecommons.org/licenses/by/4.0/.

\section{References}

Anand MO, Krishnaswamy J, Kumar A, Bali A (2010) Sustaining biodiversity conservation in human-modified landscapes in the Western Ghats: remnant forests matter. Biol Conserv 143:2363-2374. https://doi.org/10.1016/j. biocon.2010.01.013

Anderson MJ (2017) Permutational multivariate analysis of variance (PERMANOVA). Wiley StatsRef Stat Ref Online 1-15. https://doi.org/10.1002/9781118445112.stat07841

Beca G, Vancine MH, Carvalho CS et al (2017) High mammal species turnover in forest patches immersed in biofuel plantations. Biol Conserv 210:352-359. https://doi.org/10. 1016/j.biocon.2017.02.033

Benchimol M, Peres CA (2015) Predicting local extinctions of Amazonian vertebrates in forest islands created by a mega dam. Biol Conserv 187:61-72. https://doi.org/10.1016/j. biocon.2015.04.005

Benton TG, Vickery JA, Wilson JD (2003) Farmland biodiversity: is habitat heterogeneity the key? Trends Ecol Evol 18:182-188. https://doi.org/10.1016/S01695347(03)00011-9

Bhagwat SA, Willis KJ, Birks HJB, Whittaker RJ (2008) Agroforestry: a refuge for tropical biodiversity? Trends Ecol Evol 23:261-267. https://doi.org/10.1016/j.tree.2008. 01.005

Carbone C, Christie S, Conforti K et al (2001) The use of photographic rates to estimate densities of tigers and other cryptic mammals. Anim Conserv 4:75-79. https://doi.org/ 10.1017/S1367943001001081

Cardillo M, Purvis A, Sechrest W et al (2004) Human population density and extinction risk in the world's carnivores. PLoS Biol 2:0909-0914. https://doi.org/10.1371/journal. pbio.0020197

Cassano CR, Barlow J, Pardini R (2012) Large mammals in an agroforestry mosaic in the Brazilian Atlantic Forest. Biotropica 44:818-825. https://doi.org/10.1111/j.17447429.2012.00870.x

Cassano CR, Barlow J, Pardini R (2014) Forest loss or management intensification? Identifying causes of mammal decline in cacao agroforests. Biol Conserv 169:14-22 
Castilho LC, De Vleeschouwer KM, Milner-Gulland EJ, Schiavetti A (2017) Hunting of mammal species in protected areas of the southern Bahian Atlantic Forest, Brazil. Oryx. https://doi.org/10.1017/S0030605317001247

Ceballos G, Ehrlich PR (2002) Mammal population losses and the extinction crisis. Science 296:904-907. https://doi.org/ 10.1126/science. 1069349

Chao A, Gotelli NJ, Hsieh TC et al (2014) Rarefaction and extrapolation with Hill numbers: a framework for sampling and estimation in species diversity studies. Ecol Monogr 84:45-67. https://doi.org/10.1890/13-0133.1

Cushman SA, McGarigal K (2004) Patterns in the species-environment relationship depend on both scale and choice of response variables. Oikos 105:117-124. https://doi.org/10. 1111/j.0030-1299.2004.12524.x

Daily GC, Ceballos G, Pacheco J et al (2003) Countryside biogeography of neotropical mammals: conservation opportunities in agricultural landscapes of Costa Rica. Conserv Biol 17:1814-1826. https://doi.org/10.1111/j. 1523-1739.2003.00298.x

Dotta G, Verdade LM (2011) Medium to large-sized mammals in agricultural landscapes of South-eastern Brazil. Mammalia 75:345-352. https://doi.org/10.1515/MAMM.2011. 049

Estavillo C, Pardini R, Rocha PLB da (2013) Forest loss and the biodiversity threshold: an evaluation considering species habitat requirements and the use of matrix habitats. PLoS ONE 8:1-10. https://doi.org/10.1371/journal.pone. 0082369

Fahrig L (2003) Effects of habitat fragmentation on biodiversity. Annu Rev Ecol Evol Syst 34:487-515. https://doi.org/10. 1146/annurev.ecolsys.34.011802.132419

Fahrig L (2013) Rethinking patch size and isolation effects: the habitat amount hypothesis. J Biogeogr 40:1649-1663. https://doi.org/10.1111/jbi.12130

Fahrig L, Baudry J, Brotons L et al (2011) Functional landscape heterogeneity and animal biodiversity in agricultural landscapes. Ecol Lett 14:101-112. https://doi.org/10.1111/ j.1461-0248.2010.01559.x

Faria D, Laps RR, Baumgarten J, Cetra M (2006) Bat and bird assemblages from forests and shade cacao plantations in two contrasting landscapes in the Atlantic Forest of southern Bahia, Brazil. Biodivers Conserv 15:587-612. https://doi.org/10.1007/s10531-005-2089-1

Faria D, Paciencia MLB, Dixo M et al (2007) Ferns, frogs, lizards, birds and bats in forest fragments and shade cacao plantations in two contrasting landscapes in the Atlantic forest, Brazil. Biodivers Conserv 16:2335-2357. https:// doi.org/10.1007/s10531-007-9189-Z

Ferraz KMPM, de B, Siqueira, de Martin MF PS, et al (2010) Assessment of Cerdocyon thous distribution in an agricultural mosaic, Southeastern Brazil. Mammalia 74:275-280. https://doi.org/10.1515/MAMM.2010.036

Ferreira AS, Le Pendu Y, Martinez RA (2018a) The use of a mixed rubber landscape by tufted-ear marmosets. Primates 59:293-300. https://doi.org/10.1007/s10329-017-0645-4

Ferreira AS, Peres CA, Bogoni JA, Cassano CR (2018b) Use of agroecosystem matrix habitats by mammalian carnivores (Carnivora): a global-scale analysis. Mamm Rev 48:312-327. https://doi.org/10.1111/mam.12137
Fischer J, Lindenmayer DB (2007) Landscape modification and habitat fragmentation: a synthesis. Glob Ecol Biogeogr 16:265-280. https://doi.org/10.1111/j.1466-8238.2006. 00287.x

Gardner TA, Barlow J, Chazdon R et al (2009) Prospects for tropical forest biodiversity in a human-modified world. Ecol Lett 12:561-582. https://doi.org/10.1111/j.14610248.2009.01294.x

Gonçalves F, Bovendorp RS, Beca G et al (2018) Atlantic mammal traits: a dataset of morphological traits of mammals in the Atlantic Forest of South America. Ecology 19:498

Harvey CA, Gonzalez J, Somarriba E (2006) Dung beetle and terrestrial mammal diversity in forests, indigenous agroforestry systems and plantain monocultures in Talamanca, Costa Rica. Biodivers Conserv 15:555-585. https://doi. org/10.1007/s10531-005-2088-2

IBGE (2010) Census of the Brazilian population 2010. https:// www.ibge.gov.br/. Accessed 20 June 2016

Jackson HB, Fahrig L (2015) Are ecologists conducting research at the optimal scale? Glob Ecol Biogeogr 24:52-63. https://doi.org/10.1111/geb.12233

Lacher TE Jr, Davidson AD, Fleming TH et al (2019) The functional roles of mammals in ecosystems. $\mathrm{J}$ Mammal 100(3):942-964. https://doi.org/10.1093/jmammal/ gyy 183

Landau EC, Hirsch A, Musinsky J (2008) Vegetation cover and land use in the Atlantic coastal forest of Southern Bahia, Brazil, based on satellite imagery: a comparison among municipalities. In: Thomas WW, Britton EG (eds) The Atlantic coastal forest of Northeastern Brazil. The New York Botanical Garden Press, New York, pp 221-244

Laurance WF, Sayer J, Cassman KG (2014) Agricultural expansion and its impacts on tropical nature. Trends Ecol Evol 29:107-116. https://doi.org/10.1016/j.tree.2013.12. 001

Lessa ICM, Ferreguetti ÁC, Kajin M et al (2017) You can’t run but you can hide: the negative influence of human presence on mid-sized mammals on an Atlantic island. J Coast Conserv 21:829-836. https://doi.org/10.1007/s11852-0170544-2

Low-Décarie E, Chivers C, Granados M (2014) Rising complexity and falling explanatory power in ecology. Front Ecol Environ 12(7):140821075159009. https://doi.org/10. $1890 / 130230$

Luck GW (2007) A review of the relationships between human population density and biodiversity. Biol Rev 82:607-645. https://doi.org/10.1111/j.1469-185X.2007.00028.x

Magioli M, Ferraz KMPM de, Setz EZF et al (2016) Connectivity maintain mammal assemblages functional diversity within agricultural and fragmented landscapes. Eur J Wildl Res 62:431-446. https://doi.org/10.1007/s10344-0161017-x

Martensen AC, Ribeiro MC, Banks-Leite C et al (2012) Associations of forest cover, fragment area, and connectivity with neotropical understory bird species richness and abundance. Conserv Biol 26:1100-1111. https://doi.org/ 10.1111/j.1523-1739.2012.01940.x

Mazerolle MJ, Villard MA (1999) Patch characteristics and landscape context as predictors of species presence and 
abundance: A review. Écoscience 6:117-124. https://doi. org/10.1080/11956860.1999.11952204

McNeely JA, Schroth G (2006) Agroforestry and biodiversity conservation: traditional practices, present dynamics, and lessons for the future. Biodivers Conserv 15:549-554. https://doi.org/10.1007/s10531-005-2087-3

Mori SA, Boom BM (1983) Southern Bahian moist forests. Bot Rev 49:155-232. https://doi.org/10.1007/BF02861011

Odenbaugh J (2005) Idealized, inaccurate but successful: a pragmatic approach to evaluating models in theoretical ecology. Biol Philos 20:231-255. https://doi.org/10.1007/ s10539-004-0478-6

Oksanen J, Blanchet FG, Friendly M et al (2016) Vegan: community ecology package. $\mathrm{R}$ package version 2.4-0. https:// CRAN.R-project.org/package=vegan. Accessed $10 \mathrm{Oct}$ 2016

Palmer MS, Swanson A, Kosmala M et al (2018) Evaluating relative abundance indices for terrestrial herbivores from large-scale camera trap surveys. Afr J Ecol. https://doi.org/ 10.1111/aje. 12566

Pardini R, Bueno A, de A, Gardner TA, et al (2010) Beyond the fragmentation threshold hypothesis: regime shifts in biodiversity across fragmented landscapes. PLoS ONE 5:1-10. https://doi.org/10.1371/journal.pone.0013666

Pardini R, Nichols E, Püttker T (2017) Biodiversity response to habitat loss and fragmentation. In: DellaSala DA, Goldstein MI (eds) Earth systems and environmental sciences: encyclopedia of the anthropocene. Elsevier, New York, pp 229-239

Peres CA (2001) Synergistic effects of subsistence hunting and habitat fragmentation on Amazonian Forest Vertebrates. Conserv Biol 15:1490-1505. https://doi.org/10.1046/j. 1523-1739.2001.01089.x

Prado PI, Pinto LP, De Moura RT et al (2003) Caracterização dos registros de ocorrência de espécies de plantas e mamíferos no sul da Bahia, Brasil. In: Prado PI, Landau EC, Moura RT, Pinto LPS, Fonseca GAB, Alger K (eds) Corredor de Biodiversidade na Mata Atlântica do Sul da Bahia. IESB/CI/CABS/UFMG/UNICAMP, Ilhéus, Bahia, Brazil. CD-Room

R Core Team (2017) R: a language and environment for statistical computing. 3.3.2. R. Foundation for Statistical Computing, Vienna

Regolin AL, Cherem JJ, Graipel ME et al (2017) Forest cover influences occurrence of mammalian carnivores within
Brazilian Atlantic Forest. J Mammal 98:1721-1731. https://doi.org/10.1093/jmammal/gyx103

Rice RA, Greenberg R (2000) Cacao cultivation and the conservation of biological diversity. Ambio A J Hum Environ 29:167-173. https://doi.org/10.1579/0044-7447-29.3.167

Santos CLA, Le Pendu Y, Giné GAF et al (2018) Human behaviors determine the direct and indirect impacts of freeranging dogs on wildlife. J Mammal. https://doi.org/10. 1093/jmammal/gyy077

Santos PZF, Crouzeilles R, Sansevero JBB (2019) Can agroforestry systems enhance biodiversity and ecosystem service provision in agricultural landscapes? A meta-analysis for the Brazilian Atlantic Forest. For Ecol Manag 433:140-145. https://doi.org/10.1016/j.foreco.2018.10. 064

Tews J, Brose U, Tielborger K et al (2004) Animal species diversity driven by habitat heterogeneity/diversity: the importance of keystone structures. J Biogeogr 31:79-92

Thomas WW (2003) Natural vegetation types in southern Bahia. In: Prado PI, Landau EC, Moura RT, Pinto LP, Alger K, Fonseca GAB (eds) Corredor de Biodiversidade da Mata Atlântica do Sul da Bahia. IESB/CI/CABS/UFMG/UNICAMP, Ilhéus, Bahia, Brazil. CD-Room

Watson JEM, Shanahan DF, Di Marco M et al (2016) Catastrophic declines in wilderness areas undermine global environment targets. Curr Biol 26:2929-2934. https://doi. org/10.1016/j.cub.2016.08.049

Wilman H, Belmaker J, Simpson J et al (2014) EltonTraits 1.0: Species-level foraging attributes of the world's birds and mammals. Ecology. https://doi.org/10.1890/13-1917.1

Woodroffe R (2000) Predators and people: using human densities to interpret declines of large carnivores. Anim Conserv 3:165-173. https://doi.org/10.1017/ S136794300000086X

Wright SJ (2003) The myriad effects of hunting for vertebrates and plants in tropical forests. Perspect Plant Ecol Evol Syst 6:73-86

Zuur AF, Ieno EN, Walker NJ et al (2009) Statistics for biology and health. Springer, New York

Publisher's Note Springer Nature remains neutral with regard to jurisdictional claims in published maps and institutional affiliations. 